\title{
Effect of Valsalva's manoeuvre and hyoscinbutylbromide on the pressure gradient across the wall of oesophageal varices
}

\author{
S W HOSKING, P ROBINSON, AND A G JOHNSON \\ From the University Surgical Unit, Royal Hallamshire Hospital, Sheffield
}

SUMmaRY To assess whether Valsalva's manoeuvre might cause variceal bleeding, 22 patients with oesophageal varices were studied. In 12 patients who received no previous treatment to their varices the median pressure gradient across the varix wall at rest was $19(6-36) \mathrm{mmHg}$, and in 10 patients whose varices were thrombosed at their distal end the median pressure gradient in the proximal patent varix was $8(1-16) \mathrm{mmHg}$. In untreated patients groups, the pressure gradient rose by $6-12 \mathrm{mmHg}$ during Valsalva's manoeuvre in four patients, fell by $4-11 \mathrm{mmHg}$ in five patients and was virtually unchanged in the remainder. These changes seem unlikely to cause variceal bleeding. Patients who repeated Valsalva's manoeuvre showed similar changes on each occasion. Six patients in the untreated group also received hyoscinbutylbromide $20 \mathrm{mg}$ iv. No change was seen in the pressure gradient in five patients, suggesting that it is of little value in preventing variceal bleeding.

The relationship between portal or variceal pressure and bleeding from oesophageal varices is uncertain. Some studies have shown no correlation between pressure and bleeding ${ }^{12}$ whilst others suggest that the two are loosely related ${ }^{34}$ but the overlap in portal pressure between bleeding and non-bleeding patients with varices is considerable. An alternative possibility is that a sudden transient rise could start variceal bleeding. Such a rise may occur during Valsalva's manoeuvre, when varices are often seen to bulge further into the oesophageal lumen ${ }^{3}$ and potentially increasing the risk of rupture. During Valsalva's manoeuvre considerable rises in portal pressure $^{5}$ and variceal pressure ${ }^{6}$ occur but as these studies had no internal reference point it is impossible to determine the transmural pressure changes of the vessel under study. Recognising that transmural pressure is related to vessel tension (Laplace's law) and therefore risk of rupture, Reding et al have measured portal vein and oesophageal lumen pressure simultaneously and found that portal vein

Address for correspondence: Mr S W Hosking. FRCS, University Surgical Unit, Floor K, Royal Hallamshire Hospital, Sheffield S10 2JF.

Received for publication 12 February 1987. pressure rose in excess of oesophageal lumen pressure during Valsalva's manoeuvre. ${ }^{7}$ As it is the varices that bleed, however, we wished to study the transvariceal pressure gradient at rest and during Valsalva's manoeuvre to see if this is important in the aetiology of variceal bleeding. No studies to date have measured intraoesophageal and intravariceal pressures simultaneously during Valsalva's manoeuvre, which is essential to calculate the pressure gradient across the variceal wall.

As drugs may have a beneficial role in preventing variceal bleeding we also studied the effect of hyoscinbutylbromide on variceal pressure. Anticholinergic drugs (of which hyoscinbutylbromide is one) have been shown to increase the size of oesophageal varices during barium swallow examinations. ${ }^{89}$ We wished to study whether this variceal dilatation was accompanied by a fall in the pressure gradient across the variceal wall.

\section{Methods}

\section{PATIENTS}

Twenty two patients were studied. Their clinical details are shown in Table 1 . Twelve patients 
Table 1 Clinical details of patients

\begin{tabular}{lll}
\hline & Untreated & Treated \\
\hline Patients $(\mathrm{n})$ & 12 & 10 \\
Median age (range) & $49(23-73)$ years & $63(43-79$ years) \\
Aetiology of liver disease & & \\
Alcohol & 6 & 3 \\
PBC & 3 & 4 \\
Cryptogenic & 2 & 3 \\
$\quad$ Portal vein thrombosis & 1 & 0 \\
Child's grading A & 4 & 5 \\
$\quad$ B & 4 & 5 \\
$\quad$ C & 4 & 0 \\
\hline
\end{tabular}

received no previous treatment for their oesophageal varices, and 10 patients previously received sclerotherapy and were diagnosed to have fully thrombosed varices in their lowest $3 \mathrm{~cm}$. Above this level, the varices were patent, as evidenced by a changing size with respiration. Informed consent was obtained from each patient and the study was approved by the Hospital Ethical Committee.

\section{APPARATUS (Fig. 1)}

Two cannulae were used simultaneously to record intraoesophageal and intravariceal pressures. The intraoesophageal cannula (Teflon, oD $2 \mathrm{~mm}$ ) was open ended and had three holes in the terminal $1 \mathrm{~cm}$ at $120^{\circ}$ intervals. Both this and the variceal injector (PTFE oD $2.2 \mathrm{~mm} 22 \mathrm{G}$ needle) were perfused with $5 \%$ Dextrose at $0.05 \mathrm{ml} /$ minute through flow regulators (CSF Intraflow II, Sorrenson Research Co, Salt Lake City). The perfused cannulae were connected to transducers (S9B, Gaeltect, Scotland) and a chart recorder (Model 8088, Gould, Surrey, UK).

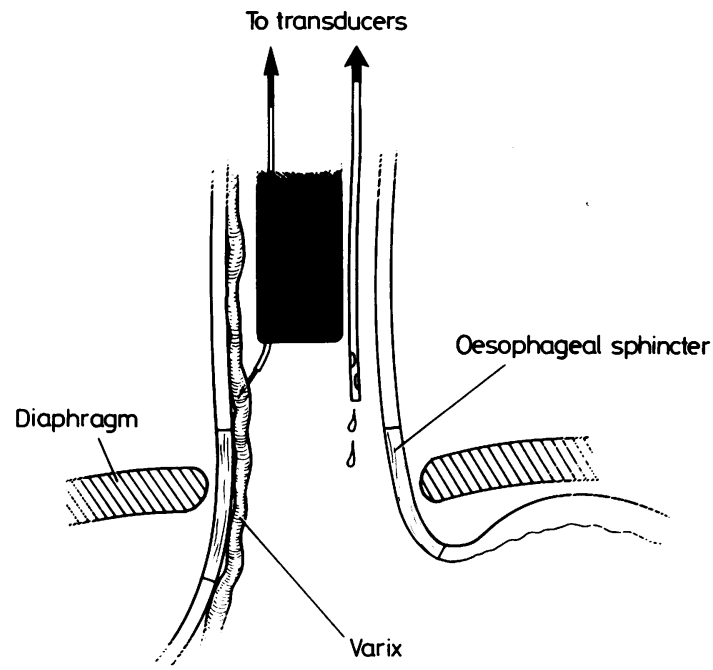

Fig. 1 Apparatus showing catheter alongside gastroscope measuring intraoesophageal pressure and needle from gastroscope measuring intravariceal pressure.
CLINICAL TECHNIQUE

After topical pharyngeal anaesthesia and light sedation (2.5-10 $\mathrm{mg}$ Diazemuls) the intraoesophageal cannula was passed. An Olympus Q-10 endoscope was then introduced to the oesophagogastric junction $(\mathrm{OGJ})$ and then withdrawn so that its tip lay $5-6 \mathrm{~cm}$ above this point. The intraoesophageal cannula tip was then positioned at the intended level of variceal assessment which was $4-5 \mathrm{~cm}$ above the OGJ. Thus, in patients whose varices were thrombosed distally, variceal puncture was done proximally in the patent part of the same varix. In each patient at least one varix was punctured and readings obtained at rest for two minutes. After this period, the midpoint of the respiratory cycle was used to obtain mean resting values for each patient. Each patient was then instructed to carry out a voluntary Valsalva's manoeuvre by asking them to bear down as if opening their bowels. Where possible, Valsalva's manoeuvre was repeated up to three times in each patient. Readings were obtained for a further half minute at rest to ensure that the needle was still in the varix, otherwise the results were discarded.

In six patients who had not had previous treatment, hyoscinbutylbromide $20 \mathrm{mg}$ iv was administered and pressures measured for a further six minutes.

After the assessment, those patients who had not had previous treatment had their varices injected. Patients who already had varices thrombosed at their lower end had no further treatment.

Bleeding from the puncture site was minimal and was easily controlled by a sleeved endoscopic balloon.

\section{VALIDATION}

Slow perfusion of recording cannulae produces instant responses to pressure changes as 'line drag' is virtually eliminated (Fig. 2). Any obstruction to perfusate flow (such as the needle lying paravariceally or against the vein wall) resulted in an extremely rapid rise in pressure to $>100 \mathrm{mmHg}$. This permitted easy identification of incorrect needle placement. Like Staritz ${ }^{10}$ we found that pressures in several varices within an individual patient were within $10 \%$ of each other. Thus we considered that a stable recording obtained for at least one minute before and after Valsalva's manoeuvre confirmed correct placement of intraoesophageal and intravariceal cannulae, and represented accurately intraoesophageal and intravariceal pressures. Reproducibility of results on more than one occasion was not checked as we considered it unethical to do repeated studies several days later and delay injection of varices. Also the variceal pressure gradient may vary from week to week and the aim of this study was to see the 

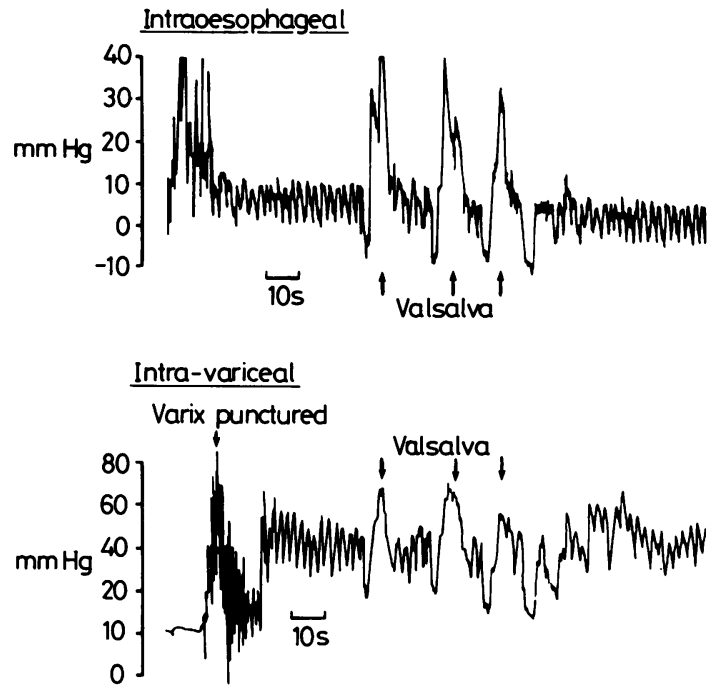

Fig. 2 Simultaneous recording of intraoesophageal and intravariceal pressures obtained at rest and during three successive Valsalva's manoeuvres in one patient (note the differing scales). The small fluctuations (every 2 secs) are respiratory.

immediate effect of various manoeuvres on this gradient.

Intraluminal oesophageal pressure may vary throughout its length during Valsalva's manoeuvre" and pressures obtained at our site of assessment $(4 \mathrm{~cm}$ above OGJ) may differ from those at the site of variceal rupture $(0-2 \mathrm{~cm}$ above OGJ). To examine this further, eight patients with oesophageal varices had their oesophageal pressure profile measurement at rest and during Valsalva's manoeuvre, carried out in the supine position. Pressures were measured by a multilumen catheter assembly containing eight perfused side holes situated $1 \mathrm{~cm}$ apart and positioned so that the lowest hole lay in the stomach. The catheters were each perfused with water at a rate of $0.5 \mathrm{ml} / \mathrm{min}$ and were connected through pressure transducers to a multichannel chart recorder. After obtaining stable basal readings, each patient was instructed to carry out Valsalva's manoeuvre three times, as described previously.

The results of three Valsalva's manoeuvres were very similar and the median result is shown in Table 2. During Valsalva's manoeuvre, pressures recorded $4 \mathrm{~cm}$ above the diaphragm were virtually the same as those recorded in the lower oesophageal sphincter.

\section{Results}

At rest, both the intravariceal pressure and the pressure gradient across the variceal wall (obtained by subtracting intraoesophageal from intravariceal
Table 2 Median pressures $(\mathrm{mm} \mathrm{Hg}$ ) obtained during three successive Valsalva's manoeuvres

\begin{tabular}{|c|c|c|c|}
\hline \multirow[b]{2}{*}{ Patient } & \multirow[b]{2}{*}{$\begin{array}{l}4 \text { cmabove } \\
\text { diaphragm }\end{array}$} & \multicolumn{2}{|l|}{ Site of measurement } \\
\hline & & $\begin{array}{l}\text { Within thoracic portion } \\
\text { of lower oesophageal } \\
\text { sphincter }\end{array}$ & Stomach \\
\hline 1 & 62 & 58 & 30 \\
\hline 2 & 52 & 55 & 74 \\
\hline 3 & 64 & 64 & 80 \\
\hline 4 & 30 & 32 & 42 \\
\hline 5 & 31 & 33 & 36 \\
\hline 6 & 36 & 36 & 42 \\
\hline 7 & 42 & 42 & 160 \\
\hline 8 & 34 & 34 & 34 \\
\hline Mean $( \pm S E)$ & $44( \pm 4 \cdot 9)$ & $44( \pm 4 \cdot 6)$ & $62( \pm 15)$ \\
\hline
\end{tabular}

pressure) varied with respiration (Fig. 2). This occurred in all patients. Median pressure gradient at rest in untreated patients was $19 \mathrm{mmHg}$ (range 6-36 $\mathrm{mmHg}$ ) and in treated patients was $8 \mathrm{mmHg}$ (range $1-16 \mathrm{mmHg})(\mathrm{p}<0 \cdot 01$ Wilcoxon's rank-sum test $)$.

During Valsalva's manoeuvre in untreated patients, intraoesophageal pressure rose to between 11 and 56 (median 29) $\mathrm{mmHg}$ and intravariceal pressures rose to between 18 and 74 (median 52) $\mathrm{mmHg}$. Figure $3 \mathrm{a}$, however, shows that the pressure gradient across the varix wall rose in some patients, remained virtually unchanged in others, and fell in the remainder. In previously treated patients, intraoesophageal pressures rose to between 11 and 44 (median 25 ) $\mathrm{mmHg}$ during Valsalva's manoeuvre and intravariceal pressure to between 19 and 60 (median 33) $\mathrm{mmHg}$. As in untreated patients, the pressure gradient rose in some patients, was unchanged in others and fell in the remainder (Fig. 3b).

In 11 patients (six treated, five untreated) results

a Noprevious sclerotherapy. Previous sclerotherapy_ b

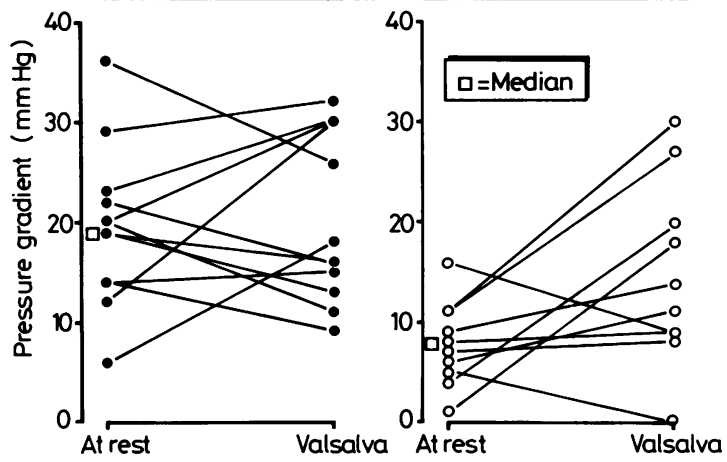

Fig. 3 Changes in pressure gradient across varix wall before and during Valsalva's manoeuvre in untreated and treated patients. 
were obtained from repeated Valsalva's manoeuvres (Table 3). These showed that (a) intraoesophageal pressures rose by different amounts with each Valsalva, (b) a consistent positive or negative change in the pressure gradient occurred, and (c) the degree of change in the pressure gradient was variable and was independent of (a).

After administration of hyoscinbutylbromide, intraoesophageal pressure remained unchanged in all six patients. Intravariceal pressure was unchanged in five patients and fell in one patient from 19-13 $\mathrm{mmHg}$. No patient suffered from any complications after the pressure assessments.

\section{Discussion}

Measuring intravariceal pressure by fine needle puncture has proved to be a safe procedure, both by others $^{12}$ and ourselves. It was easier to puncture and obtain satisfactory recordings from large varices than from small varices. Despite recordings being made with an endoscope in place, we were satisfied that patients were able to carry out a Valsalva's manoeuvre satisfactorily and our intraoesophageal pressure readings confirmed this.

It has been suggested that bleeding occurs when the tension of the variceal wall reaches a critical point - the rupture point. ${ }^{3}$ The tension of the varix wall is defined by Laplace's law as $T=\left(P_{1}-P_{2}\right) R / T$ where $P_{1}$ is the pressure inside the varix, $P_{2}$ is the pressure outside the varix (intraoesophageal pressure), $r$ is the radius and $t$ its thickness. Earlier intravascular pressure studies have shown Valsalva's manoeuvre to cause a rise in portal pressure ${ }^{5}$ and intravariceal

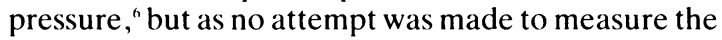
simultaneous rise in abdominal or thoracic pressures, the results are of little value in predicting variceal rupture.

The alternative pneumatic membrane technique of measuring intravariceal pressure ${ }^{+}$is less invasive and is reported to give almost identical pressure readings when compared with needle puncture methods. ${ }^{13}$ Unfortunately the device measures pressure in relation to atmospheric rather than intrathoracic or intraoesophageal pressures which prevents its use in measuring the pressure gradient across the varix wall in its present form.

Reding et $a l^{7}$ were the first to measure simultaneous intra- and extravascular pressure in relation to the portal system during Valsalva's manoeuvre, by comparing portal pressure with intraoesophageal pressure. This comparison of intraabdominal portal pressure with intraoesophageal (intrathoracic) pressure is difficult to interpret for two reasons. First, others $^{14}$ and ourselves have found that pressures within the abdomen differ from those in the thorax
Table 3 Results of repeated Valsalva's manoeuvres within untreated and treated patients

\begin{tabular}{|c|c|c|c|c|c|}
\hline \multirow[b]{2}{*}{ Patient } & \multirow[b]{2}{*}{$\begin{array}{l}\text { Resting } \\
\text { intra- } \\
\text { oesophageal } \\
\text { pressure }\end{array}$} & \multirow[b]{2}{*}{$\begin{array}{l}\text { Resting } \\
\text { intra- } \\
\text { variceal } \\
\text { pressure }\end{array}$} & \multicolumn{3}{|c|}{ Valsalva's manoeuvre } \\
\hline & & & $\begin{array}{l}\text { Intra- } \\
\text { oesophageal } \\
\text { pressure }\end{array}$ & $\begin{array}{l}\text { Intra- } \\
\text { variceal } \\
\text { pressure }\end{array}$ & $\begin{array}{l}\text { Change in } \\
\text { pressure } \\
\text { gradient }\end{array}$ \\
\hline \multicolumn{6}{|c|}{ (a) Untreated } \\
\hline \multirow[t]{3}{*}{1} & 0 & 21 & 23 & 32 & -11 \\
\hline & () & 21 & 26 & 40 & -7 \\
\hline & () & 21 & 25 & 4() & -6 \\
\hline \multirow[t]{3}{*}{2} & 3 & 40 & 40 & 66 & -11 \\
\hline & 3 & 40 & 33 & 55 & -15 \\
\hline & 3 & 40 & 20 & 45 & -12 \\
\hline \multirow[t]{3}{*}{3} & 2 & 33 & 32 & 52 & -11 \\
\hline & 2 & 33 & 16 & 29 & -18 \\
\hline & 2 & 33 & 17 & 25 & -23 \\
\hline \multirow[t]{3}{*}{4} & -3 & 20 & 22 & 70 & +25 \\
\hline & -3 & 20 & 16 & 70 & +31 \\
\hline & -3 & 20 & 36 & 68 & +9 \\
\hline \multirow[t]{2}{*}{5} & 3 & 17 & 28 & 62 & +20 \\
\hline & 3 & 17 & 30 & 56 & +12 \\
\hline \multirow[t]{3}{*}{6} & 0 & 13 & 28 & 37 & -4 \\
\hline & () & 13 & 28 & 35 & -6 \\
\hline & 0 & 13 & 24 & 37 & () \\
\hline \multicolumn{6}{|c|}{ (b) Treated } \\
\hline \multirow[t]{3}{*}{1} & 5 & 11 & 26 & 43 & +11 \\
\hline & 5 & 11 & 24 & 42 & +12 \\
\hline & 5 & 11 & 35 & 46 & +5 \\
\hline \multirow[t]{3}{*}{2} & 2 & 10 & 12 & 19 & -1 \\
\hline & 2 & 10 & 16 & 21 & -3 \\
\hline & 2 & 10 & 17 & 21 & -4 \\
\hline \multirow[t]{3}{*}{3} & 5 & 10 & 18 & 23 & +5 \\
\hline & 5 & 10 & 21 & 35 & +15 \\
\hline & 5 & 10 & 21 & 36 & +14 \\
\hline \multirow[t]{3}{*}{4} & 3 & 15 & 28 & 42 & +2 \\
\hline & 3 & 15 & 25 & 42 & +5 \\
\hline & 3 & 15 & 20 & 48 & +16 \\
\hline \multirow[t]{2}{*}{5} & 4 & 13 & 32 & 33 & -8 \\
\hline & 4 & 13 & 14 & 16 & -6 \\
\hline
\end{tabular}

All resting pressures are taken at midpoint of respiratory cycle and are in $\mathrm{mmHg}$.

during Valsalva's manoeuvre and secondly, although portal pressure correlates well with variceal pressure it is usually significantly higher. ${ }^{12}{ }^{13}$ Thus, no transmural pressure gradients were measured, either of portal vein or oesophageal varices.

Staritz et al recently measured intraoesophageal pressure during Valsalva's manoeuvre and then measured intravariceal pressure during a separate Valsalva's manoeuvre." They calculated the pressure gradient assuming that the intraoesophageal pressure developed during each Valsalva's manoeuvre was identical. This assumption is not supported by our data. We consider it essential to do simultaneous readings of intraoesophageal and intravariceal pressures so that the pressure gradient across the variceal wall is known at all times. Unlike Staritz et al, we found that although Valsalva's manoeuvre produced a rise in intravariceal pressure in all patients, 
the variceal pressure gradient rose in some patients and in others there was a marked fall. It may be that in some patients, alternative portal systemic anastomoses can accommodate the increased portal systemic flow occurring during Valsalva's manoeuvre, without causing a rise in the variceal pressure gradient. An alternative explanation is that in some patients intra-abdominal pressure rises above intrathoracic pressure during Valsalva's manoeuvre and in others the reverse is true as seen in our patients undergoing oesophageal manometry. The different pressure gradients observed within each of our patients during repeated Valsalva's manoeuvres, may indicate a varying distribution of portasystemic flow at differing intrathoracic pressures. If Valsalva's manoeuvre does cause variceal bleeding, it would be more probable in those patients who show a rise in their variceal pressure gradient. Even so, the pressure rises were not large and seem unlikely to initiate bleeding. This is in keeping with a retrospective study of women with varices who became pregnant and had a vaginal delivery (involving repeated sustained Valsalva's manoeuvres). ${ }^{\text {Is }}$ Sixty one vaginal deliveries occurred in 50 patients and only one patient bled from her varices during the second stage of labour.

In those patients with varices thrombosed at their lower end, resting pressures recorded proximally in the same varices were significantly lower than in untreated patients. This probably reflects adequate sclerosis in the lowest $2-3 \mathrm{~cm}$ of oesophageal varices and could be a useful test for this in clinical practice. Blood probably reaches the proximal varix via perforating oesophageal veins. ${ }^{16}$ The range of resting pressures $(1-16 \mathrm{~mm} \mathrm{Hg})$ and the changes occurring during Valsalva's manoeuvre may reflect the number of perforators and the proportion that are thrombosed.

The value of drugs in lowering variceal pressure has considerable appeal. The conflicting results obtained with propranolol in the prevention of variceal haemorrhage ${ }^{1718}$ have prompted the effect of drugs including isosorbide, ${ }^{19}$ glyceryl trinitrate ${ }^{11}$ and somatostatin ${ }^{211}$ on variceal pressure to be evaluated. Of these only somatostatin has been used effectively in isolation to arrest variceal bleeding ${ }^{21}$ but others have found it less effective in clinical use. ${ }^{22}$ The ability of anticholinergic drugs to improve the visibility of varices during a barium swallow is interesting. They may act by relaxing the lower oesophageal sphincter ${ }^{2.3}$ and allowing increased flow through varices normally tightly encircled by the LOS. As these drugs also inhibit peristalsis, increased flow through veins perforating a relaxed oesophageal musculature may contribute to their increased diameter. Both our study and another where a higher dose of hyoscinbutylbromide $(40 \mathrm{mg})$ was used (Staritz unpublished data) indicate that this drug has no consistent effect on intravariceal pressure. Thus it appears to have little place in the prevention or arrest of variceal bleeding by reducing variceal pressure. Its effect of reducing perstalsis, however, as well as possibly increasing variceal size may well facilitate injection sclerotherapy. Our technique of measuring the variceal pressure gradient will allow other drugs to be evaluated in this way.

Part of this work was presented at the British Society of Gastroenterology and appeared in abstract form in Gut.

\section{References}

1 Lebrec D, De Fleury P, Rueff B, et al. Portal hypertension, size of oesophageal varices and risk of gastrointestinal bleeding in alcoholic cirrhosis. Gastroenterology 1980; 79: 1139-44.

2 Palmer ED, Brick IB. Correlation between the severity of esophageal varices in portal cirrhosis and their propensity towards haemorrhage. Gastroenterology 1956; 30: 85-90.

3 Garcia-Tsao G, Groszmann RJ, Fisher RL, et al. Portal pressure, presence of gastro-esophageal varices and variceal bleeding. Hepatology 1985; 5: 419-24.

4 Gertsch P, Loup P, Diserens H, et al. Endoscopic noninvasive manometry of esophageal varices: prognostic significance. Am J Surg 1982; 144: 528-30.

5 Burcharth F, Bertheussen $\mathrm{K}$. The influence of posture, Valsalva manoeuvre and coughing on portal hypertension in cirrhosis. Scand J Clin Lab Invest 1979; 39: 665-9.

6 Palmer ED. Effect of the Valsalva manoeuvre on portal hypertension in cirrhosis. Am J Med Sci 1954; 227: 661-2.

7 Reding P, Urbain D, Grivegnee A, Frere Daniel. Portal venous-esophageal luminal pressure gradient in cirrhosis. Hepatology 1986; 6: 98-100.

8 Ghahremani, GG, Port RB, Winans CS, Williams JR. Esophageal varices - enhanced radiologic visualization by anticholinergic drugs. Dig Dis 1972; 17: 703-12.

9 Waldram R, Nunnerly H, Davis M, et al. Detection and grading of oesophageal varices by fiberoptic endoscopy and barium swallow with and without Buscopan. Clin Radiol 1977; 28: 137-41.

10 Staritz M, Poralla T, Meyer ZUM, et al. Intravascular oesophageal variceal pressure (IOVP) assessed by endoscopic fine needle puncture under basal conditions, Valsalva's manoeuvre and after glyceryl trinitrate application. Gut 1985; 26: 525-30.

11 Pellegrini CA, De Meester T, Skinner DB. Response of the distal esophageal sphincter to respiratory and positional manoeuvres in humans. Surg Forum 1976; 27: 380-2.

12 Westaby D, Gimson A, Williams R. Oesophageal varix pressure measurement: the relation to portal pressure 
and the responses to changes in intraabdominal pressure [Abstract]. Gut 1985; 26: A562.

13 Bosch J, Bordas JM, Rigau J, et al. Noninvasive measurement of the pressure of esophageal varices using an endoscopic gauge: comparison with measurements by variceal puncture in patients undergoing endoscopic sclerotherapy. Hepatology 1986; 6: 667-72.

14 Fedail SS. Harvey RF, Burns-Cox CJ. Abdominal and thoracic pressures during defecation. Br Med J 1979; i: 91 .

15 Britton RC. Pregnancy and oesophageal varices. Am J Surg 1982; 143: 421-5.

16 McCormack TT, Smith PM, Rose JD, et al. Perforating oesophageal veins and blood flow in oesophageal varices. Lancet 1983; ii: 1442-4.

17 Burroughs AK, Jenkins WJ, Sherlock DBE, et al. Controlled trial of propranolol for the prevention of recurrent variceal hemorrhage in patients with cirrhosis. N Engl J Med 1983; 309: 1539-42.

18 Lebrec D, Poynard T, Bernau J, et al. A randomized controlled study of propranolol for prevention of recurrent gastrointestinal bleeding in patients with cirrhosis: A final report. Hepatology 1984; 4: 355-8.

19 Dawson J, Gertsch P, Mossiman F, et al. Endoscopic variceal pressure measurements: response to isosorbide dinitrate. Gut 1985; 26: 843-7.

20 Clements D, Rhodes JM, Elias E. Effect of somatostatin on oesophageal variceal pressure assessed by direct measurement. J Hepatol 1986; 2: 262-6.

21 Jenkins SA, Baxter JN, Corbett W, et al. A prospective randomised controlled clinical trial comparing somatostatin and vasopressin in controlling acute variceal haemorrhage. Br Med J 1985; 290: 275-8.

22 Kravetz D, Bosch J, Teres J, et al. Comparison of intravenous somatostatin and vasopressin infusions in treatment of acute variceal hemmorhage. Hepatology 1984; 4: 442-6.

23 Dickson RC, Stewart J, Sidorov JJ, et al. The effect of anticholinergic drugs on the motility of the esophagus. Gastroenterology 1972; 42: 750 . 